\title{
CONDUCTIVITY OF LITHIUM HEPTAGERMANATE GLASSES AND SINGLE CRYSTALS DOPED WITH 3d- IONS
}

\author{
M.M. Koptiev*, M.P. Trubitsyn, M.D. Volnianskii, O.O. Nesterov \\ Oles Honchar Dnipro National University, Dnipro, Ukraine \\ *e-mail:davurika@gmail.com
}

\begin{abstract}
Lithium heptagermanate $\mathrm{Li}_{2} \mathrm{Ge}_{7} \mathrm{O}_{15}$ glasses doped with $\mathrm{Cr}$ and $\mathrm{Mn}$ were prepared by the melt quenching. Electrical conductivity $\sigma$ of pure and doped glasses was measured in $\mathrm{AC}$ field $(f=1 \mathrm{kHz})$ within the temperature range 300-700 K. It is shown that both impurities increase conductivity of the glasses. The influence of $\mathrm{Cr}$ doping is very subtle whereas the maximal effect is observed for the $\mathrm{Li}_{2} \mathrm{Ge}_{7} \mathrm{O}_{15}$ : Mn glass. The obtained data are compared with the results of measuring $\sigma$ in $\operatorname{Li}_{2} \mathbf{G e}_{7} \mathbf{O}_{15}: \mathrm{Cr}$, Mn single crystals. It is noted that doping affects $\sigma$ of the glasses and single crystals in different ways. In particular, the conductivity of the single crystals can be controlled by doping in a wide range: introducing $\mathrm{Cr}$ impurity strongly increases $\sigma$ and vice versa doping with Mn sufficiently decreases $\sigma$ value. Doping effect is interpreted on the basis of the previous EPR data giving information on the location of $\mathrm{Cr}$ and Mn centers in the $\mathrm{Li}_{2} \mathrm{Ge}_{7} \mathrm{O}_{15}$ structure. $\mathrm{Cr}$ ions substitute for $\mathrm{Ge}$ ions and are fixed within oxygen octahedra. On the other hand, Mn ions are located within the cavities formed by $\mathrm{Ge}-\mathrm{O}$ structural framework and are assumed to be mobile enough to contribute to charge transfer.
\end{abstract}

Keywords: ionic conduction, doping, glass, single crystal, lithium heptagermanate $\mathrm{Li}_{2} \mathrm{Ge}_{7} \mathrm{O}_{15}$.

Received 12.11.2018; Received in revised form 8.12.2018; Accepted 21.12.2018

\section{Introduction}

Development of modern electronics and energetics stimulates interest to ionic conduction phenomena in solids. The most actual problem is a limited term of solid electrolytes exploitation in power supplies and batteries. One of the promising ways is to replace organic electrolytes with inorganic solids and in particular with complex oxides. The last should be more electrically stable that allows achieving much more charge cycles. Of course, ionic conductance is strongly dependent on atomic, micro- and nanometer sized structures of the solid. It is of interest to study ionic transport in ordered and specifically disordered solids with the same chemical composition. In particular, the role of long- and short-range ordering may be revealed by the comparative analysis of ionic conduction in amorphous and single crystalline solids.

Family of lithium-germanium oxides $\mathrm{Li}_{2} \mathrm{O}-x \mathrm{GeO}_{2}$ includes about ten stable compounds [1], some of which are considered as the perspective matrixes for creating new superionic conductors. As well known, doping with heterovalent impurities can be an effective approach to increase ionic conductivity. This paper is devoted to investigations of $\mathrm{AC}$ electrical conductivity of lithium heptagermanate $\mathrm{Li}_{2} \mathrm{Ge}_{7} \mathrm{O}_{15}$ glasses doped with $\mathrm{Cr}$ and $\mathrm{Mn}$ impurities. The data obtained for glasses are compared with the results measured for $\mathrm{Li}_{2} \mathrm{Ge}_{7} \mathrm{O}_{15}: \mathrm{Cr}, \mathrm{Mn}$ single crystals.

\section{Experimental results}

Pure and doped with $\mathrm{Cr}(0.06 \mathrm{wt} \%)$ and $\mathrm{Mn}(0.06 \mathrm{wt} \%)$ lithium heptagermanate glasses were obtained by quenching the melts as described in [2-4]. The estimated quenching rate was about $\sim 10^{3} \mathrm{~K} / \mathrm{s}$. Electrical properties were measured in AC field $(f=1 \mathrm{kHz})$ by using AC bridges E7 - 10 and Tesla BM - 507. The samples were cut as the plane-parallel plates with $5 \times 5 \mathrm{~mm}^{2}$ sizes and of about $1 \mathrm{~mm}$ thickness. Pt electrodes were deposited on the main planes of the samples by vacuum sputtering. Measurements were performed on heating run from 300 $\mathrm{K}$ to $700 \mathrm{~K}$. The upper limit of this interval was chosen enough below the glass transition temperature $T_{g}=775 \mathrm{~K}[2,3]$ in order to keep unchanged the amorphous state of the samples during a measuring cycle. 
2.1. Conductivity of $\mathrm{Li}_{2} \mathrm{Ge}_{7} \mathrm{O}_{15}: \mathrm{Cr}, \mathrm{Mn}$ glasses. Usually, increase of conductivity on heating is described by the expression

$$
\sigma(T)=\frac{A}{T} \exp \left(-E_{\sigma} / k_{B} T\right),
$$

where $E_{\sigma}$ is an activation energy; $k_{B}$ is Boltzmann constant; the proportionality factor is given by $A=n q^{2} \delta^{2} v /\left(z k_{B}\right)$, here $n, q$, and $\delta$ are the concentration, charge and hopping length of carriers, respectively; $v$ is a frequency of lattice vibrations; $z$ represents the number of nearest available positions. In accord with (1), the data obtained for pure and doped with $\mathrm{Cr}$ and $\mathrm{Mn}$ glasses are plotted in Arrhenius scale in Fig. 1a. For all the samples in the studied temperature interval, $\sigma(1 / T)$ dependences show nearly linear behavior with the slopes, which are close to each other $\left(E_{\sigma}=0.90 \pm 0.01 \mathrm{eV}\right)$. One can see that doping with $\mathrm{Cr}$ and $\mathrm{Mn}$ impurities increases conductivity of $\mathrm{Li}_{2} \mathrm{Ge}_{7} \mathrm{O}_{15}$ glass. At that introducing $\mathrm{Cr}(0.06 \mathrm{wt} \%)$ has only very subtle effect and increases conductivity by no more than one and a half times. Introducing Mn impurity with the same concentration $(0.06 \mathrm{wt} \%)$ has more appreciable effect - conductivity increases in about five times.
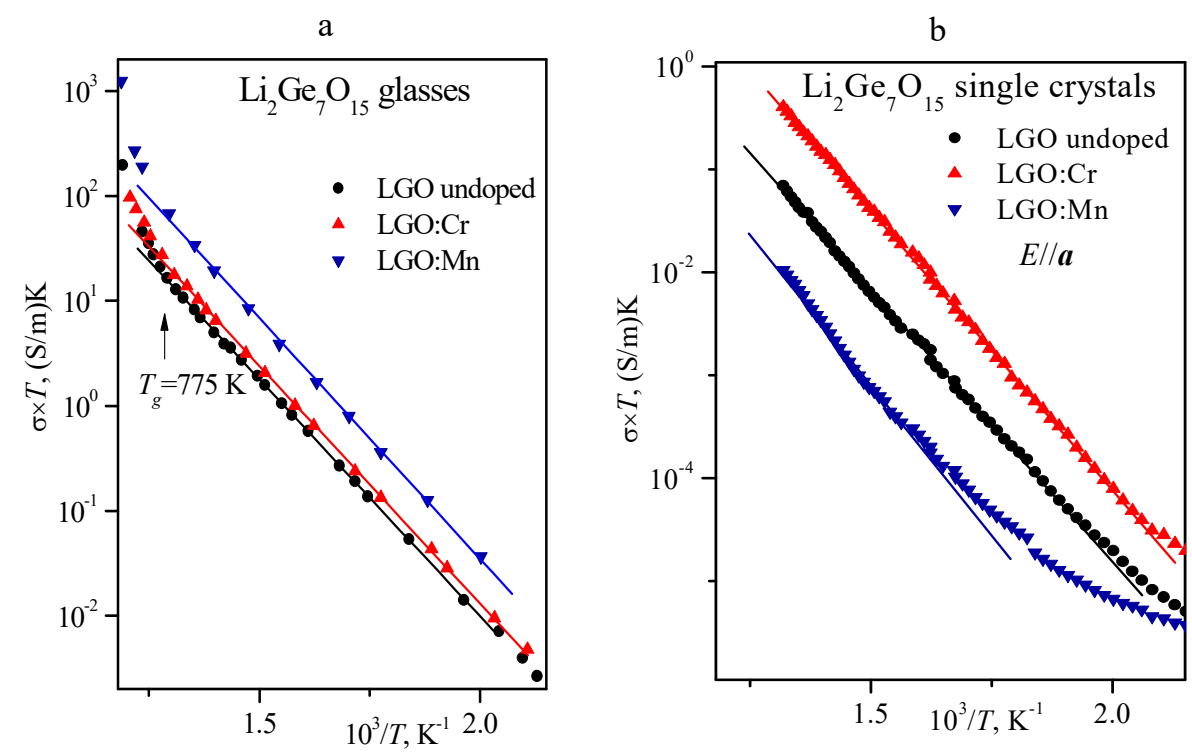

Fig. 1. Dependence of the product $(\sigma \times T)$ on $(1 / T)$ for pure and doped $\mathrm{Li}_{2} \mathrm{Ge}_{7} \mathrm{O}_{15}$ : glasses (a) and single crystals (b). Measurements were performed in $\mathrm{AC}$ field $(f=1 \mathrm{kHz})$. For the single crystals measuring field was directed along $a$ axis [5].

2.2. Conductivity of $\mathrm{Li}_{2} \mathrm{Ge}_{7} \mathrm{O}_{15}: \mathrm{Cr}$, Mn single crystals. $\mathrm{Cr}$ and $\mathrm{Mn}$ doping effect on $\sigma$ in $\mathrm{Li}_{2} \mathrm{Ge}_{7} \mathrm{O}_{15}$ single crystal was studied in the previous work [5]. The temperature dependences of conductivity for pure and doped with $\mathrm{Cr}(0.1 \mathrm{wt} \%)$ and $\mathrm{Mn}(0.03 \mathrm{wt} \%)$ single crystals are presented in Ahrrenius scale in Fig. 1b. One can see that doping with $\mathrm{Cr}$ increases $\sigma$ value, whereas doping with $\mathrm{Mn}$ appreciably lowers $\sigma$. It is remarkable that in the glassy and single crystalline $\mathrm{Li}_{2} \mathrm{Ge}_{7} \mathrm{O}_{15}$ the effects of $\mathrm{Cr}$ and $\mathrm{Mn}$ impurities on $\sigma$ are qualitatively different (Figs. 1a and b). Such discrepancy may be attributed to long-range ordering, which is absent in amorphous state and is the basic feature of a single crystal. In addition, the structure of the impurity centers could be important. 


\section{Discussion}

In paraelectric phase $\left(\mathrm{T}>\mathrm{T}_{\mathrm{C}}=283 \mathrm{~K}\right)$ the structure of $\mathrm{Li}_{2} \mathrm{Ge}_{7} \mathrm{O}_{15}$ crystal corresponds to space symmetry group $\mathrm{D}_{2 \mathrm{~h}}{ }^{14}(b>c>a)$ [6]. In the previous paper it was shown [7] that conductivity of $\mathrm{Li}_{2} \mathrm{Ge}_{7} \mathrm{O}_{15}$ single crystal was strongly anisotropic - along $\boldsymbol{a}$ axis $\sigma$ in one and two orders exceeds typical $\sigma$ values along $\boldsymbol{c}$ and $\boldsymbol{b}$ axes, correspondingly. This anisotropy is correlated with directions of structural channels containing Li ions [6]. Mobile defects in Li1 and Li2 sublattices can move along $\boldsymbol{a}$ axis. Conductivity along $\boldsymbol{c}$ axis is contributed by only the defects in Li2 sublattice which can move through the less wide channels. There are no channels along $\boldsymbol{b}$ axis and in this direction $\mathrm{Li}^{+}$motion is restricted.

The models of $\mathrm{Cr}$ and $\mathrm{Mn}$ centers in $\mathrm{Li}_{2} \mathrm{Ge}_{7} \mathrm{O}_{15}$ single crystal were proposed on the basis of EPR data ([8-11] and the refs therein). It was shown that $\mathrm{Cr}$ ions produced excess to stoichiometry $\mathrm{Li}$ interstitials $\left(\mathrm{A}_{\mathrm{Li}}\right)$ and formed $\mathrm{Cr}^{3+}-\mathrm{Li}^{+}$pair centers. In contrast, $\mathrm{Mn}^{2+}$ centers produced $\mathrm{Li}$ vacancies $\left(\mathrm{V}_{\mathrm{Li}}\right)$, which could trap $\mathrm{A}_{\mathrm{Li}}$ and decreased their concentration. So, doping with $\mathrm{Cr}$ or $\mathrm{Mn}$ ions enables us to control the concentration of $\mathrm{A}_{\mathrm{Li}}$ and $\mathrm{V}_{\mathrm{Li}}$. Measuring $\sigma$ in $\mathrm{Li}_{2} \mathrm{Ge}_{7} \mathrm{O}_{15}: \mathrm{Cr}$, Mn should clarify what the defects determine the charge transfer. The effect of $\mathrm{Cr}$ and $\mathrm{Mn}$ doping on $\sigma$ (Fig. $1 \mathrm{~b}$ ) evidences that above $500 \mathrm{~K}$ charge transfer in $\mathrm{Li}_{2} \mathrm{Ge}_{7} \mathrm{O}_{15}$ single crystal is determined by $\mathrm{A}_{\mathrm{Li}}$ moving along the structural channels.

One can believe that the structural framework of $\mathrm{Li}_{2} \mathrm{Ge}_{7} \mathrm{O}_{15}$ glass is formed by $\mathrm{Ge}-\mathrm{O}$ tetrahedra and octahedra linked by bridging oxygen ions. In that case the main difference of the $\mathrm{Li}_{2} \mathrm{Ge}_{7} \mathrm{O}_{15}$ glass structure from the single crystalline one is the absence of longrange ordering. Then conductivity of undoped $\mathrm{Li}_{2} \mathrm{Ge}_{7} \mathrm{O}_{15}$ glass could be attributed to motion of $\mathrm{Li}$ ions which are located in the cavities formed by $\mathrm{Ge}-\mathrm{O}$ structural skeleton and weakly bound to it. Such supposition is confirmed by the results of $\sigma(T)$ studying in the $\mathrm{Li}_{2} \mathrm{O}-x \mathrm{GeO}_{2}(x=7,11.5,18)$ glasses [12]. The concept of lattice site (and consequently the concepts of $\mathrm{A}_{\mathrm{Li}}$ and $\mathrm{V}_{\mathrm{Li}}$ ) in amorphous phase loses its physical meaning. Thus, in glass much more $\mathrm{Li}$ ions become weakly bound and can move through the cavities formed by disordered $\mathrm{Ge}-\mathrm{O}$ structural framework. Accordingly, conductivity of undoped glass increases in 2-3 orders in comparison with undoped single crystal (see Figs. 1a and $\mathrm{b}$ ).

The positions of $\mathrm{Cr}$ and $\mathrm{Mn}$ ions in the structure of $\mathrm{Li}_{2} \mathrm{Ge}_{7} \mathrm{O}_{15}$ glass can be assumed analogous as in $\mathrm{Li}_{2} \mathrm{Ge}_{7} \mathrm{O}_{15}$ single crystal [8-11]. That is, $\mathrm{Cr}^{3+}$ substitute for $\mathrm{Ge}^{4+}$ within $\mathrm{Ge}-\mathrm{O}$ octahedra, whereas $\mathrm{Mn}^{2+}$ are located within the cavities formed by $\mathrm{Ge}-\mathrm{O}$ framework. In that case the effects of $\mathrm{Cr}$ and Mn doping on glass conductivity (Fig. 1a) can be attributed to impurity ion motion. Cr ions are fixed within $\mathrm{GeO}_{6}$ octahedra and can not move in the external electric field. Mn ions, located within wide enough cavities, are weakly bound to structural skeleton and can contribute to conduction.

\section{Conclusion}

Conductivity of pure and doped with $\mathrm{Cr}$ and $\mathrm{Mn}$ lithium heptagermanate glasses was studied in AC field. It is shown that doping by both impurities increases conductivity. At that the effect of Mn doping is much more pronounced in comparison with $\mathrm{Cr}$ dopant. Doping effect in glass is compared with the results of conductivity measurements in $\mathrm{Li}_{2} \mathrm{Ge}_{7} \mathrm{O}_{15}: \mathrm{Cr}, \mathrm{Mn}$ single crystals. It is proposed that doping influence on conductivity of glass can be explained by impurity ion contribution to charge transfer. 


\section{References}

1. Murthy, M.K. Studies in germanium oxide systems: I. Phase equilibria in the system $\mathrm{Li}_{2} \mathrm{O}-\mathrm{GeO}_{2}$ / M.K. Murthy // J. Am. Ceram. Soc. - 1964. - Vol. 47, No. 7. - P. 328 - 331. doi: 10.1111/j.1151-2916.1964.tb14433.x

2. Volnyanskii, M.D. Thermal and electrical properties of glass-ceramics based on lithium heptagermanate / M.D. Volnyanskii, A.A. Nesterov, M.P. Trubitsyn // Physics of the Solid State. - 2012. - Vol. 54, No. 5. - P. 945-946. doi: $10.1134 /$ S1063783412050459

3. Volnianskii, M.D. Devitrification of the $\mathrm{Li}_{2} \mathrm{O}-\mathrm{x}\left(\mathrm{GeO}_{2}\right)$ glass / M.D. Volnyanskii, O.O. Nesterov, M.P. Trubitsyn // Ferroelectrics. - 2014. - Vol. 466, No. 1. - P. 126 130. doi: 10.1080/00150193.2014.895173

4. Nesterov, O.O. Ionic conductivity in multiphase $\mathrm{Li}_{2} \mathrm{O}-7 \mathrm{GeO}_{2}$ compounds / O.O. Nesterov, M.P. Trubitsyn, S.G. Nedilko, M.D. Volnianskii, S.M. Plyaka, Ya.O. Rybak // Acta Phys. Polonica. - 2018. - Vol. 133, No. 4. - P. 892 - 896. doi: 10.12693/APhysPolA.133.892.

5. Trubitsyn, M.P. Ionic conduction in $\mathrm{Li}_{2} \mathrm{Ge}_{7} \mathrm{O}_{15}$ crystals doped with $\mathrm{Cr}$ and $\mathrm{Mn}$ ions / M.P. Trubitsyn, M.D. Volnianskii, A.H. Obaidat Yahia // Physics of the Solid State. - 2008. - Vol. 50, No. 7. - P. $1234-1237$.

6. Iwata, Y. Neutron diffraction study of structural phase transition in ferroelectric $\mathrm{Li}_{2} \mathrm{Ge}_{7} \mathrm{O}_{15} /$ Y. Iwata, I. Shibuya, M. Wada, A. Sawada, Y. Ishibashi // J. Phys. Soc. Jpn. 1987. - Vol. 56, No. 7. - P. 2420 - 2427.

7. Volnianskii, M.D. Anisotropy of the electrical conductivity of lithium heptagermanate crystals / M.D. Volnianskii, M.P. Trubitsyn, A.H. Obaidat Yahia // Physics of the Solid State. - 2008. - Vol. 50, No. 3. - P. $422-424$.

8. Trubitsyn, M.P. EPR of $\mathrm{Mn}^{2+}$ ions in lithium heptagermanate crystal / M.P. Trubitsyn, M.D. Volnyanskii, A.Yu. Kudzin // Kristallografiya. - 1991. - Vol. 36, No. 6. - P. 1472.

9. Trubitsyn, M.P. EPR study of the ferroelectric phase transition in $\mathrm{Li}_{2} \mathrm{Ge}_{7} \mathrm{O}_{15}: \mathrm{Cr}^{3+}$ crystal / M.P. Trubitsyn, M.D. Volnyanski, I.A. Busoul // Physics of the Solid State. - 1998. - Vol. 40, No. 6. - P. 1006 - 1008.

10.Volnianskii, M. Dielectric relaxation of $\mathrm{Cr}^{3+}-\mathrm{Li}^{+}$pair centers in $\mathrm{Li}_{2} \mathrm{Ge}_{7} \mathrm{O}_{15}$ crystals / M. Volnianskii, M. Trubitsyn, A.H. Obaidat, Yahia // Physics of the Solid State. - 2007. - Vol. 49, No. 8. - P. 1453 - 1456.

11.Volnianskii, M.D. EPR and dielectric spectroscopy of reorienting $\mathrm{Cr}^{3+}-\mathrm{Li}^{+}$pair centres in $\mathrm{Li}_{2} \mathrm{Ge}_{7} \mathrm{O}_{15}$ crystal / M.D. Volnianskii, M.P. Trubitsyn, A.H. Obaidat Yahia // Condensed Matter Physics.- 2007.- Vol. 10, No. 1 (49). - P. 75 - 78.

12. Volnyanskii, M.D. Thermal and electrical properties of glass-ceramics based on lithium heptagermanate / M.D. Volnyanskii, A.A. Nesterov, M.P. Trubitsyn // Physics of the Solid State. - 2012. - Vol. 54, No. 5. - P. 945 - 946. 